\title{
Translation of Words with Cultural Image
}

\author{
Fenfang Li \\ School of Foreign Languages and Literature, Yangtze Normal University, Fuling, Chongqing, China \\ Email: tracy842005@163.com \\ Shiyang Ran \\ School of Foreign Languages and Literature, Shandong University, Jinan, China \\ School of Foreign Languages and Literature, Yangtze Normal University, Fuling, Chongqing, China \\ Email: ranshiyang888@yahoo.com.cn \\ Tian Xia \\ School of Foreign Languages and Literature, Yangtze Normal University, Fuling, Chongqing, China \\ Email: 448358094@qq.com
}

\begin{abstract}
Cultural image is a kind of cultural symbol, which carries unique, wide, deep cultural connotations. The default and misplacement of cultural images caused by cultural differences always put translators in dilemma. The differences in cultural images between the source and target language frequently cause semantic default and contextual conflicts in the process of transference and present a hard nut for the translator to crack. Due to the close relationship between language and culture, unique cultural images are formed in the languages of different nations. In the process of translation, as a cross-language and cross-cultural activity, the cultural image of the original words should be expressed and the cultural meanings should be transmitted as appropriately and completely as possible. While in practical translation, translators always find it difficult to choose an almost equal word to replace the original one, thus the problems of misplacement, loss in the translation of words with cultural image come out, which cause difficulties and misunderstandings in the intercultural communication. In this paper it is to present the status quo of translating words with cultural image and illustrate their unique meaning in different cultures. Then it is to discuss some problems caused in translation activities. Finally it is to expound the upmost principle for translating cultural images: foreignizing translation. Based on foreignization, several suitably acceptable methods are introduced in this paper as well: to transplant the original images faithfully by means of image retention and notes and image addition in order to achieve the purpose of cross-cultural communication, which will make translation more suitable for the purpose of cultural intercommunication.
\end{abstract}

Index Terms - words with cultural image, translation, foreignization, approaches

\section{INTRODUCTION}

As translation involves two different languages which are the carriers of their respective cultures, it is not only a transfer between languages but also a communication between cultures. With the increasingly frequent cultural exchanges and communication among people between China and foreign countries, people now have higher and higher demands not only for the enjoyment of fluency, beauty and grace, but also for the accessibility to exotic culture in translation. As for the higher demand to translation of words with cultural image, the translators always fall into the dilemma that they "can not have both bear's paw and the fish at the same time". Frequent international culture exchanges lead to a higher requirement for translation of words with cultural image: the translated version should be elegant and fluent; furthermore, it should express the distinctive cultural images of the origin version. The neglect of their meaning and transmission will affect the proper expression of the whole content and the understanding of the artistic conception and figures. Traditionally researchers focus on the meaning and equivalence of the original expression, while in translation of words with cultural image the cultural image is the core of certain culture and in translation translators had better give out the deep connotation of cultural image, which will make target readers interested in different cultures and recognized the difference of different cultures, as a result it will realize the purpose and significance of translation and cultural intercommunication. In this paper it is to find out the problems in translation of words with cultural image and examine the misplacement and loss in the translation of words with cultural image. In addition, it will expound the upmost principle for translating cultural images: to realize the cultural images of original expression faithfully by means of foreignizing translation. Based on foreignization, several suitably acceptable methods are introduced in this paper as well: to transplant the original images faithfully by means of image retention and notes and image addition in order to achieve the purpose of cross-cultural communication, which will make translation more suitable for the purpose of cultural intercommunication.

\section{WORDS WITH CULTURAL IMAGE}


Culture image is formed in many thousand years of history in every nation, and "it is the crystallization of the long-term developing history and culture of different ethnics; some are closely related to national legends or totem worship. In all years of the long history of their ethnics, they continue to appear in the language of the people inside, and in literary and artistic works generation after generation. They slowly developed into a cultural symbol with a relatively fixed, a unique cultural meaning, some of which even have an extensive and far-reaching image association. When people mention it, they understand it tacitly and are good to communication." (Xie Tianzhen 1999:26)When people talk about it, a common image or implication is there, that is culture image, which is unique and specialized in its nation's culture. Words with cultural image are those words which have some kind of hidden implication behind the literal meaning, and when people use such kind of words, they mean some special and unique meanings. Words with cultural image have two features: national specificity and context-dependence. Although human thoughts share the common physiology and content, due to the objective natural and social environment, it is quite different in ways of thinking and language for the same content. As linguists say, people in different ethnics see the phenomenon of the same objective, different ethnic languages will give it different colors on the brush, which reflects the cultural characteristics of their ethnic and historical imprint, thus creating a culture of imagery with the attribution of nationality. ${ }^{(1)}$ Cultural image is generated in the cultural environment of a cultural symbol, thus having a feature of context-dependence. Cultural Images and semantic reasoning are necessary to conform to the context. While context changed, cultural imagery and semantics may change according to the context. The original meaning is the weather process of rapid cooling caused by large-scale cold winds. However, when it used to describe the mood of someone, it means a bad or sorrowful mood. Belongingness of cultural image of a nation also determines that people must sometimes choose different cultural images required to convey English language content into Chinese in order to reach the same culture reference in the process of translation. So words with cultural image have the context-dependence. In the translation of such kind of words, translators should pay more attention to the context and translators should put more attention on the translation of such kind of words with cultural image.

\section{SOME PROBLEMS IN THE TRANSLATION OF WORDS WITH CULTURAL IMAGE}

\section{A. Misplacement in the Translation of Words with Cultural Image}

Different cultures more or less lead to the differences in the way of understanding of its people. The differences of the languages make a difficult crack to cross in the international communication. In translation, there are some words or phrases with cultural characteristics that can not be translated equally, thus appearing the misplacement of translation of words with cultural image. Misplacement of translation of words with cultural image prevents the target readers from losing the chance to have a distinctive and real access to the original work, which do harm to the international culture exchanges and understanding. Because of different surroundings, the same objective objects represent different or opposite culture image in different cultures. While people always translate the original words with cultural image from superficial meanings, this is misplacement of cultural image. The non-proficiency of the origin language and the target language, or culture makes misplacement of translation occur.

In Chinese culture, Loong ${ }^{(2)}$ has an important status and a great influence on Chinese culture. Since ancient times, Loong in Chinese culture is an important part of Chinese philosophy. The masses always love Loong, awe dragon as well as worship it. Loong in Chinese culture, as a cultural phenomenon, has penetrated into all aspects of Chinese society, becoming a culture of cohesion and accumulation. During the development of Loong culture, whether the evolution of the image of Chinese Loong or the evolution of the implication of Loong culture, all reflected the creation of the Chinese nation and implied the Chinese nation's future faith and spiritual sustenance. Because of this, at home and abroad, Chinese see themselves as descendants of the Loong and are proud of that. As to every Chinese, Loong image is a symbol and a kind of flesh and blood emotion. In addition to the dissemination and inheritance of the Chinese Loong culture in China, it also crossed the waters and spread all over the world and enroot there. Loong images and "Loong dances" (sometimes dragon dances) can be seen everywhere in Chinatown in Western countries, all these indicate the influence of the Chinese culture of Loong. Thus, the image of the Loong, as a spiritual symbol of Chinese culture and national totems, has been deeply imprinted in every Chinese people's mind. Loong is a symbol of the Chinese nation, which is an auspicious animal. Loong in Chinese culture is not only a totem in China, but also has a profound cultural background. Han Chinese are known for their "Descendants of the Loong". In the ancient Chinese, loong is a symbol of the emperor, noble, majestic, imposing and a symbol of authority, the emperors also called themselves "true sons of the Loong". So, with the "dragon" related idiom, such as "prosperity brought by the dragon and the phoenix", "Crouching Tiger Hidden Dragon" and so on, it is always with a compliment. "Loong" also take command of all the location, such as "national champions", "big boss", etc.

While in Longman Dictionary of Contemporary English (2004:167), dragon is defined as: (1) a large imaginary animal that has wings and a long tail and can breathe out fire4; (2) a woman who behaves in an angry and unfriendly way. In western culture, the Dragon often looks like demons, as the opposite of the heroes. While in literal works, it has

\footnotetext{
(1) Http://www.lunwenwang.com/Freepaper/English

(2) Loong is transliterated from the Chinese express "Long"(龙), whose equivalent is "dragon" in many E-C dictionaries. To distinct its deep meaning and formal difference to English word "long", in the paper it is translated as "Loong", which is discussed by many scholars before.
} 
an image of wickedness, especially for women, it symbolizes malicious and cruel women, and the image of dragon is negative. In early western story, dragon was a kind of monster, a symbol of evil. In the Bible, dragon was the symbol of evil. In British epic Beowulf, the hero Beowulf also fought fiercely with an evil dragon which is to protect treasure. From these definitions the dragon is a bad feature. Therefore "Dragon" is considered to be a gas-filled high-handed and aggressive monster. In English, the "dragon" always related to multi-band derogatory idioms: If we say that a woman is a "dragon", which refers to that she is a violent old woman; another example: "She is a bit of a dragon around this place" means "she was a very pull addiction to people". Thus "dragon" have become the symbol of terror and terrible in English. Studying its source, in the Western myth, "dragon" is a kind of monster shaped like a huge lizard, long wings, scaly bodies, dragging a long tail, and with its mouth spitting fire with the murderous smoke. Therefore, "dragon" caused by the association with the Han Chinese "Dragon" is entirely different.

In English-Chinese translation, people always translate Loong into Dragon and vice versa, which ignore the different connotations of two cultures and does not meet the spirit of the times. In Chinese culture, Loong is ubiquitous. It is no exaggeration to say that the Loong culture constitute the foundation and the thrust of Chinese culture. Its role is to act as messengers reaching heaven, rain animal and lucky miraculous objects etc. However, dragon in Western culture has a quite different meaning. Therefore, Loong in Chinese is quite different from Dragon in English. If people mix them together, it may be easier for them to have intercultural misunderstanding.

\section{B. Loss in the Translation of Words with Cultural Image}

Translation has been becoming increasingly prominent in disseminating cultural information, and promoting further mutual understanding between different ethnics and national integration. In the practical process of translation activities, the impersonal heterogeneity of ethnic language and culture will inevitably bring objective obstacles to the exchange of information. Among them, the extreme heterogeneity of language and culture, as a form of cultural expression, lead the translation into a dilemma. Cultural loss is a common phenomenon, and cultural image often has been neglected. Because of the differences that exist in cultures among many countries, there are some words or phrases with cultural characteristics that can not be translated properly. Or translators could not find an almost equal expression to replace the original one. By presenting the example of Qiangshou who is to replace the examinees in the examination, it is to propose some counter measures to solve the problem, aiming at finding out the effective ways and measures.

In recent years, the term "qiangshou" frequently appears in various media. "Qiangshou" as a social phenomenon, although not big flood, but at least has been quietly popular. When close to all major examination period, the streets, online forums, "qiangshou" are looming on the ads. Almost without exception, "qiangshou" appears where examinations take place. In China, a person who sits for an examination for someone is commonly known as qiangshou, who contains cultural implication. Yet many English lexicon and newspapers fail to convey its accurate cultural meaning. In recent years, the term gunmen frequent in various media. "Qiangshou" in English can be divided into the following:

a: Explanatory Translation

"qiangshou": one who sits for an examination in place of another person. (in Modern Chinese-English Dictionary1999:1081); substitute during examination on false pretenses (in Lin Yutang's Chinese-English Dictionary of Modern 1972:682); one who sits for the real candidate in an examination (in Liang Shiqiu's New Practical Chinese-English Dictionary 1970:958).

b: Literal Translation

“qiangshou”: a hired gun (in China Daily 2004-07-16); a gunmen (in China Daily 2005-01-11).

c: Free Translation

"qiangshou": a substitute (in China Daily, Hongkong Edition, 2003-06-24); a substitute tester (in China Daily, Hongkong Edition, 2003-10-08); a substitute examinee, a hired examinee (Liang Shiqiu's New Practical Chinese-English Dictionary); examinee substitute (New Century Chinese-English Dictionary).

At the first sight, translating "qiangshou" into "a hired man" or "gunman", it seems to be able to convey the authentic image of "qiangshou" to English readers with its culture, however, it is actually a distortion of history and culture. According to Modern Chinese Dictionary, the unstressed word "shou" means one who sits for an examination in place of another person, while the rising tone "shǒu" has a totally different meaning: armed soldiers or shooter. According to Xu Huilan's research (2005: 95), the reasons why the "qiangshou" is used and analyzed as the following: The shape of the brush that the ancients used to write poetry composition is similar to the Hong Yingqiang, while sitting for an examination in place of another person is not a glorious thing, so they always use "qiang" (gun) to replace "bi" (pen), thus calling the person who sits for an examination in place of another person "qiangshou" (qiāngshou). What's more, according to the record in Tang Dynasty, people call the person who is skilled at something "-shou". So "qiangshou" is used based on it. Perhaps because years have passed, people almost forget the replacement between "qiang" and "bi" so as to translate "qiangshou" into "gunmen" or "hired man". In fact, "qiangshou" has nothing to do with gun or something related to it. Or if they have some relationship between, it still can not translate "qiangshou" into "gunmen" or "hired man". According to Longman Dictionary of Contemporary English, "a hired man" means someone who is paid to shoot someone else; "gunmen" means a criminal or TERRORIST who use a gun. Both are related to killer or criminal, it is really wrong to translate "qiangshou" into "gunmen" or "hired man". So we cannot find the same or equal word in English to replace "qiangshou", because Chinese have a totally different implication in the word "qiangshou". 
In translation, the implicit beauty and the vague beauty are not reflected in English. This is because Chinese is a semantic-based language. In thousands of years, under the influence of emphasis on meaning, demeanor and strength of character and aesthetic traditions, Chinese formed the grammatical structure of an inherent relationship, implicit relations and fuzzy relations. Chinese culture image is easily missing in the English language. A better approach is to add footnote or endnote to complement the interpretation in the text.

In conclusion, the values, aesthetics, and cultural differences such as psychological and symbolic, as well as the impact of religious beliefs and mythological figures cause English and Chinese cultural differences. To deal with these differences, when translate words with cultural Images, the translator in particular, should pay more attention to cultural context and convey cultural information in translation.

\section{PRINCIPLE OF TRANSLATING WORDS With CULTURAL IMAGE}

Translation is not simply the transformation between the languages and the language symbols. It is an activity of cross-language and cross-culture communication in the actual sense. In dealing with the cultural factors of English and Chinese translation, the translator should be willing to use pragmatic empathy in order to esteem and fit the target language's culture.

The famous translation theorist, Nida (from Wang Yining 2004:110) has pointed out that for real success in terms of translation, it is more important to learn two different cultures than languages, words make sense only in their cultural background. In the treatment of handling translation of cultural differences, translation profession has been divided into two main opposite standpoints, which are Domestication and Foreignization. Domestication promotes the use of a culture all in its own way of expression, but against the introduction of the expressions in the source language. Foreignization advocates the preservation of the unique expression in the source language and input it into the target language. Domestication is one of the principles to translate the words with cultural image of the source language into target language which readers are familiar with. It is convenient for readers to reach the degree of transformation, and it goes against the principle of faith. It is not conducive to cultural exchange and dissemination. However, one of the missions of translation is the cultural exchange and dissemination, that is, to introduce the language and the culture of one nation to another, enabling readers to appreciate the exotic culture and unique charm of verse, thus improve inter-ethnic tolerance and respect for other cultural awareness. This is Foreignization. As a famous representative of Foreignization theory in translation, Lawrence Venuti (1995/2004) highlights Foreignization in the source language. Materialist epistemology believes that epistemic has the features of limitation and limitlessness. The essence of the cultural convergence is the gradual understanding and acceptance of the exotic culture, thus having the features of limitation and limitlessness. The main aspect is the limitlessness. The main trend in cultural evolution is the convergence, that is, with the cultural development, more and more tend to unify the various cultures. As long as there is still a culture, and cultural convergence process is endless. Language is not only a carrier of culture, but also a tool for the exchange of different cultures. Foreignization will no doubt help narrow the gap between cultures, and play an important role in showing culture, characteristics, and broaden the reader's perspectives and promote cultural convergence. On the contrary, the limitlessness of cultural convergence has made Foreignization an inevitable trend of translation.

Through time and space, external and internal, the economy, politics, morality, and many other social factors, which composed culture of ethnic groups for examining personality and social psychology, ethnic spirit and features, are the focus of translation. Every work has the mark of ethnic culture. Translated works introduce the life of another nation to the reader of different cultural backgrounds to enhance understanding and communication between people, this is the fundamental purpose of the translation.

With the rapid development of science and technology, globalization and information technology help to facilitate the integration throughout the world. There are more and more frequent contacts in politics, commerce, science and technology, culture and other areas. Modern people use a more mature psychology to feel and understand other countries or cultures through radio, television, the Internet and other channels while a more open mind constantly adjust to, enrich and update their own culture psychologically. This requires that translators should not only be content to convey the general meaning of the original cultural image, but convey the maximum possible information of the source original culture as their duty.

Reception theory believes that the readers have certain expectation, requirements and psychological preparation in understanding and acceptance of foreign cultures. Therefore, they often take the initiative to understand the text of the difference with the help of reading experience, context and related notes, etc. As the exchanges between different cultures and integration, there is no need to worry for the readers of this ability.

Foreignization is Beneficial to Cross-Culture Communication. Culture is a broad and complex concept, with broad and narrow sense. Culture in the broad sense: the sum of the material and spiritual wealth created in the process of social and historical development of mankind including material culture, system culture and psychological cultural; Culture in the broad sense: people's social customs, lifestyles and relationships, etc. Culture has a distinct nationality difference. Since national geographical, ecological environment, socio-political economic system, historical background,

\footnotetext{
(8) Http://www.lunwenwang.com/Freepaper/English/principle/principle of translation
} 
customs, values and behavior patterns are different, and their culture has its own characteristics. In addition to differences in culture, culture has the features of penetration and openness. First of all culture itself was an open system, with incalculable absorption inclusive. New things of foreign culture are easily accepted by people, and absorb it into their own culture. Second, the power of cultural penetration grasp all the opportunity to enter the social life of other cultures, relying on the cultural environment where could maintain their vitality.

Because of the differences in culture, there is a need to communicate. Translation is the social exchange process and communication tool between two languages. Its purpose is to promote the language of the political, economic and cultural progress. Its mission is to convey the logic images of the real world of the original works from one language to another language. The fundamental task of translation and the great significance is cultural exchanges and promotion of cultural progress. It can be said that cultural differences determines the need for translation, the openness and permeability of culture has provided translatability for the translation.

With modern technology, especially the network's popularity in the global and the booming in the international economy, the world has entered a new era. Globalization is no longer the exclusive economic terms, and it is the main theme of our times and dramatically changes the political, economic, cultural and social life all over the world. The era of globalization will inevitably bring about the globalization of culture. The cultural interaction between nations, mutual penetration and mutual exchange, mutual integration put forward higher requirements to the translators. That only the basic information required to convey the original, just domestication to make the readers understand the translation has been difficult to adapt to the requirements of a new era. Age of globalization requires cultural exchanges and cultural integration, cultural exchange and cultural integration, on the contrary, requires Foreignization and asks the translator to convey the unique culture of the original image as complete and accurate as possible. Foreignization contributes to enrich Chinese language and culture. People may worry that the introduction of non-Chinese-style language will undermine the purity of normative of the Chinese language. They advocated domestication, in order to maintain their independence. In fact, any language does not exist in isolation. The independence and affinity of a language to the other language, it is both the protection, inheritance, development, and even update their own respective cultures. The strategy of Foreignization by the translation predecessors in China has made indelible contribution to the enrich Chinese language and culture, thus we have the vibrant and vivid words and phrases like "two birds with one stone," "trojan horse", "Aladdin's lamp," "Pandora's box" and so. Foreignization played a pivotal role in developing and enriching our language and cultural. Foreignization could not only take good appropriation of foreign countries, we can also send us the essence for sharing. Since ancient times, China has well-known great writers and famous quotes. In the end, whether Chinese literary work cannot match others' literary works? Or is the quality of Chinese translation not high? Perhaps Chinese translators should consider the issue. Therefore, the Chinese translators who translate Chinese literature into foreign languages, they should remember to introduce our excellent culture, as much as possible, but not chase for easier understanding, which will lead to the loss of Chinese characteristics and charm, but also the difficulty to go beyond the works in their mother tongue of foreign countries. So Foreignization is good to diffuse Chinese culture to other countries.

In fact when the translators translate foreign works into Chinese, as long as there are similar Chinese words, they will give up the cultural connotation carried in foreign languages, but choose similar Chinese words the readers are familiar with. This leads to the misplacement and loss in the translation of words with culture image. So Foreignization is a good way to keep this kind of unique features. Translators, as a cultural bridge between China and the world, have the responsibility to introduce the original image that readers are not familiar with and make them slowly recognized and accepted.

\section{SOME ApProaches to Translation OF Words With CUltural IMAGE}

\section{A. Image Retention and Notes}

Image Retention means the readers should get closer to the original and keep heterogeneous components in the original works. Translation is the bridge of cultural exchanges, rather than mutual gains. In translation, accurate content and fluent expression and the pursuit of exotic and forms of aesthetic value are important. Readers should have both the value of literature appreciation and conducive to cultural transmission. Therefore, the cultural characteristics of the text can not easily be replaced.

In Chinese classic A Dream of Red Mansions, the heroine Lin Daiyu is described as “心较比干多一䛎, 病如西子 胜三分”, and Yang Xianyi translates this sentence with notes as "She looked more sensitive than Pikan", more delicate than Hishi ${ }^{2} . "$

Notes: 1 A prince noted for his great intelligence at the end of Shang Dynasty.

2 A famous beauty of the ancient Kingdom of Yueh. (Yang Xianyi and Gladys Yang vol. 1 1978:48) ${ }^{(4)}$

Pikan was the embodiment of wisdom, and Hishi was the embodiment of beauty in the history of China. Yang adopts image retention and notes to introduce the cultural background in order to inform the English readers a better

\footnotetext{
(4) The Chinese classic Hong Lou Meng (红楼梦) is translated by David Hawkes, Yang Xianyi and his wife Gladys Yang respectively. However Hawkes translates the title of the novel as The Story of the Stone, and Yang translates it as The Dream of Red Mansions, therefore for the convenience in the paper, it is not necessary to mention the original book, just consider the two translation by Hawkes and Yang.
} 
understanding of cultural connotations of Pikan and Hishi legends. Although the English readers do not know Pikan and Hishi before, according to the notes, they have a better understanding as well as a closer touch to Chinese culture.

\section{B. Image Addition}

Because of cultural differences, those cultural images closely related to political, economic, religious, historical, geographical and others, which need to be explained completely and more clearly to make sure the target readers absorb and understand cross-cultural translation flawlessly.

In translating the same sentence above-mentioned, David Hawkes changes it as "She had more chambers in her heart than the martyred Bi Gan; And suffered a little more pain in it than the beautiful Xi Shi (Warring States)." (Hawkes vol. 1 1973:103)

Here, the English readers may not know who Bi Gan and Xi Shi are, but the image addition tell them Bi Gan is an intelligent person and $\mathrm{Xi}$ Shi is a beautiful lady. And the two persons are symbols of wisdom and beauty in Chinese history, and also in the eyes of Chinese. Then the purpose of translation is to let the target readers get the accurate meaning but also convey the different culture to the foreign countries.

Yang Xianyi's translation and Hawkes' version are different. For Yang, he adopts Foreignization to make foreign readers learn more about Chinese culture and literature, while Hawkes hopes his readers like to read his translation and understand the story clearly. Therefore, the translation of the words with the cultural image is a challenge for the translators. So, choosing the appropriate translation methods is essential to retain the cultural image. To some extent, Foreignization bring defamiliarization ${ }^{(5)}$ to the readers, however, it is the defamiliarization that cause the readers' curiosity about the source language cultures. Readers then take the initiative to understand and learn the source language culture of the country, to extend and deepen their aesthetic process of the idea. As for defamiliarization, Foreignization is a good way to make the readers closer to the source language and culture, thus getting better understanding of its culture. From a broader sense, the two cultures have generated a real trial of strength and communication, and played a role in exchange each other's needs and enrich their language and culture. In this sense, Foreignization makes its cultural image realized.

\section{CONCLUSION}

As the Chinese and English are different in religious beliefs, customs, geography, political systems and human history, cultural misplacement, loss and conflicts will inevitably appear in the culture. In this paper, the main focus lies in the analysis of Foreignization in translating words with cultural image, including the possibility and the advantages of Foreignization in the translation, especially in translating some unique culture implication. Based on this principle, in this paper some problems in translating words with cultural images and approaches are discussed further, and it can be concluded that misplacement and loss of cultural image in translation are frequent and obvious, therefore in translation the principle of foreignization can solve these problems, as a result in translation of words with cultural image, image retention and notes, and image addition can be used for readers' better understanding. As for the higher demand to translation of cultural image, the translators, with the spirit of love to the translation and the responsibility to the readers, should spare no efforts to give full explanation of the culture of the source language and seriously compared it with the target culture and analyze the source language and culture as much as possible in order to transplant the implication to the target language, making them shining in the target language, so that it reaches the successful intercultural communication for people from two cultures.

\section{REFERENCES}

[1] Foreign Language Teaching and Research Press (eds.) (1999). Modern Chinese-English Dictionary. Beijing: Foreign Language Teaching and Research Press.

[2] Hawkes, David (trans.) (1973). The Story of the Stone (vol.1). Middlesex: Penguin Books.

[3] Liang Shiqiu (eds.) (1970). New Practical Chinese-English Dictionary. Taipei: The Far East Book Company.

[4] Lin Yutang (eds.) (1972). Chinese-English Dictionary of Modern. Hong Kong: Hong Kong Chinese University Press.

[5] Longman press company (eds.) (2004). Longman Dictionary of Contemporary English. Beijing: Foreign Language Teaching and Research Press.

[6] Nida, E.A. (1993). Language, Culture, and Translating. Shanghai: Shanghai Foreign Language Education Press.

[7] Venuti, Lawrence (1995/2004). The Translator's Invisibility. Shanghai: Shanghai Foreign Language Education Press.

[8] Xie, Tianzhen (1999). Translatology. Shanghai: Shanghai Foreign Language Education Press. (in Chinese)

[9] Xu Huilan (2005). About Qiangshou. Journal of Higher Correspondence Education. Vol. 18 No. 1 (in Chinese)

[10] Yang Xianyi and Gladys Yang (trans.) (1978). A Dream of Red Mansions (vol.1). Peking: Foreign Language Press.

[11] Wang Yining (2004). Approaches to cultural difference in translation from the aspect of adaptation and alienation. Journal of Henan Mechanical and Electrical Engineering College. (in Chinese)

\footnotetext{
(5) http://en.wikipedia.org/wiki/Defamiliarization
} 
Fenfang Li was born in Jiangxi of People's Republic of China in 1984. She received her MA degree in Teaching Methodology of EFL from Jiangxi Normal University, China in 2008. She is currently an assistant teacher from the School of Foreign Languages, Chongqing Yangtze Normal University, Fuling, Chongqing, People's Republic of China. Her research interests include Second Language Acquisition, theory and practices of Teaching English as a Foreign Language, translation studies and translation teaching.

Shiyang Ran was born in Chongqing of People's Republic of China in 1976. He received his MA degree in E-C translation theories and practice from Chongqing Normal University, China in 2008. He is a doctoral student from Foreign Languages and Literature in Shandong University, Jinan, Shandong, People's Republic of China, in Translation Studies. He is also currently a lecturer from the School of Foreign Languages, Chongqing Yangtze Normal University, Fuling, Chongqing, People's Republic of China. His research interests include translation theories, applied translation studies and translation teaching.

Tian Xia was born in Hubei of People's Republic of China in 1988. She is currently a graduate in the School of Foreign Languages, Chongqing Yangtze Normal University, Fuling, Chongqing, People's Republic of China. She is going to get her bachelor degree from Chongqing Yangtze Normal University in 2010. 